\title{
Reintervenção endodôntica e clareamento endógeno de dentes anteriores escurecidos: relato de caso
}

Endodontic reintervention and endogenous dental bleaching of discolored anterior teeth: case report Reintervención endodóntica y aclaramiento endógeno de dientes anteriores oscurecidos: reporte de caso Marcos Sousa ROCHA ${ }^{1}$

Talita Fernanda Carneiro DA CUNHA Naildo Aguiar CORDEIRO ${ }^{3}$ Tiago Silva DA FONSECA ${ }^{4}$

${ }^{1}$ Graduado em Odontologia pela Universidade Nilton Lins (UNL), 69058-030, Manaus - AM, Brasil

${ }^{2}$ Especialista em Dentística e Endodontia: Professora do Curso de Graduação em Odontologia, Universidade Nilton Lins (UNL), 69058-030, Manaus - AM, Brasil ${ }^{3}$ Especialista em Endodontia; Professor do Curso de Graduação em Odontologia, Universidade Nilton Lins (UNL), 69058-030, Manaus - AM, Brasil ${ }^{4}$ Especialista, Mestre e Doutor em Endodontia; Professor do Curso de Graduação em Odontologia, Universidade Nilton Lins (UNL), 69058-030, Manaus - AM, Brasil; Professor do Curso de Graduação em Odontologia, Escola de Ciências da Saúde, Centro Universitário do Norte (UniNorte), 69020-030, Manaus - AM, Brasil

\section{Resumo}

O tratamento endodôntico permite a permanência de dentes na cavidade oral. No entanto, procedimentos inadequados podem ocasionar o escurecimento dentário, acometendo a estética do sorriso e levando à baixa autoestima do paciente. O objetivo do presente estudo é relatar um caso clínico de retratamento endodôntico não cirúrgico, seguido de clareamento endógeno em dentes anteriores escurecidos para reabilitar os elementos tanto funcional quanto esteticamente. Paciente do gênero feminino, 25 anos, compareceu à clínica de Odontologia de uma Universidade relatando insatisfação com seu sorriso. A queixa principal se fundamentava na baixa autoestima em decorrência do escurecimento dos incisivos central e lateral superiores esquerdos após tratamento endodôntico realizado oito meses antes. Ambos os dentes estavam assintomáticos, mas clinicamente exibiam exposição de guta-percha sem selamento coronário. Radiograficamente o elemento 21 apresentava sobre-extensão de material obturador. A conduta adotada foi a reintervenção endodôntica dos elementos 21 e 22 com sepultamento do fragmento de guta-percha extrarradicular e posterior clareamento dentário interno, além de restaurações em ambos os elementos. O retratamento endodôntico não cirúrgico e o clareamento endógeno foram eficazes para a resolução do caso, pois possibilitaram a manutenção dos elementos dentários em função na cavidade oral e o restabelecimento da estética do sorriso, garantindo satisfação da paciente.

Descritores: Endodontia; Retratamento; Clareamento Dental.

\section{Abstract}

Endodontic therapy is indicated to promote healthy dental conditions to maintain teeth in the oral cavity. However, some failures can lead to unsuccessful treatment. Inadequate procedures potentially could induce tooth pigmentation, impairing smile aesthetics and leading to the low self-esteem of the patient. In these conditions, an endodontic reintervention and a dental bleach should be performed to reestablish aesthetic status. This paper aims to report non-surgical endodontic retreatment followed by endogenous dental bleaching to restore both functions and aesthetics of anterior discolored teeth. A 25-years old female patient attended to Dental School of a university reporting dissatisfaction with her smile. Her main complaint was based on low self-esteem, due to pigmentation of central and lateral upper left incisors after endodontic treatment performed eight months before the examination. To solve her condition, the adopted treatment plan was endodontic reintervention with subsequent internal dental bleaching and thereafter restorations of both teeth. The non-surgical endodontic retreatment, as well as the endogenous bleaching, were effective in the solution of this case, once this approach allowed teeth preservation and restored smile aesthetics, assuring the satisfaction of the patient.

Descriptors: Endodontics; Retreatment; Tooth Bleaching.

\section{Resumen}

El tratamiento endodóntico permite que los dientes permanezcan en la cavidad oral. Sin embargo, los procedimientos inadecuados pueden causar oscurecimiento dental, afectando la estética de la sonrisa y disminuyendo la autoestima del paciente. El objetivo del presente estudio es presentar un caso clínico de retratamiento endodóntico no quirúrgico, seguido de aclaramiento endógeno en dientes anteriores oscurecidos para mantener las piezas dentales funcionales y esteticas. Paciente de 25 años de edad acudió a una clínica dental en una universidad informando que no estaba satisfecha con su sonrisa. La queja principal fue una baja autoestima debido al oscurecimiento de los incisivos central y lateral superiores izquierdos después del tratamiento endodóntico realizado ocho meses antes. Ambos dientes se encontraban asintomáticos, pero clínicamente se observaba gutapercha expuesta y sin sellado coronal. Radiográficamente la pieza 21 tenía una sobreextensión del material obturador. El tratamiento fue la reintervención endodóntica de los elementos 21 y 22 sepultando el fragmento extraradicular de gutapercha y posteriormente blanqueamiento dental interno, además de restauraciones en ambos elementos. El retratamiento endodóntico no quirúrgico y el aclaramiento endógeno fueron efectivos para resolver el caso, ya que permitieron mantener las piezas dentales funcionales en la cavidad oral y mantener la estética en la sonrisa, asegurando la satisfacción de la paciente.

Descriptores: Endodoncia; Retratamiento; Blanqueamiento de Dientes.

\section{INTRODUÇÃO}

O objetivo fundamental do tratamento endodôntico é permitir a permanência dos dentes em função na cavidade bucal sem comprometer a saúde do paciente ${ }^{1}$. O notável surgimento de novos materiais, novas técnicas e novas tecnologias na Endodontia levam a elevados índices de sucesso na terapia endodôntica, apesar de não ser raro deparar-se na clínica com pacientes cujo tratamento fracassou, constatado através de sinais e sintomas ${ }^{2,3}$. Apesar dos esforços para que se alcance sucesso clínico, falhas podem ocorrer e é possível lançar mão da reintervenção endodôntica para que se mantenha os dentes em função ${ }^{4}$.
O insucesso endodôntico pode estar relacionado à persistência de bactérias no canal radicular, falta de domínio técnico do profissional, como erros nos procedimentos de preparo biomecânico, obturação insatisfatória, canais não tratados, canais obturados, porém expostos à saliva por perda do selamento temporário, restaurações inadequadas, microinfiltrações, perfurações iatrogênicas e fraturas de instrumentos ${ }^{1,5}$. Alguns tratamentos endodônticos ou técnicas inapropriadas podem ocasionar complicações estéticas, especificamente o escurecimento dentário ${ }^{6}$. Dentre as principais etiologias do escurecimento em dentes 
desvitalizados estão a presença de materiais obturadores na câmara pulpar, remanescentes de tecido pulpar após o tratamento endodôntico, necrose pulpar e algumas medicações intracanal, como o iodofórmio $^{7-9}$. Nos elementos anteriores, alterações na coloração podem desencadear implicações psicológicas, prejudicando a estética do sorriso e levando à baixa autoestima do paciente ${ }^{7,8}$.

Em casos de insucesso endodôntico, faz-se necessária uma nova intervenção no canal, com a finalidade de reverter a falha da terapia anterior e tornar $\mathrm{o}$ dente novamente funcional ${ }^{1,5}$. A reintervenção convencional, sempre que possível, é selecionada como primeira alternativa de tratamento, por ser tida como um procedimento menos invasivo em comparação à cirurgia parendodôntica, apresentando baixo custo e bom prognóstico ${ }^{10,11}$. Essencialmente, o retratamento não cirúrgico consiste na desobturação dos canais radiculares, reinstrumentação, desinfecção e reobturação dos sistemas de canais para permitir o reparo das estruturas e tecidos de suporte ${ }^{12-14}$.

Um dos maiores desafios do retratamento endodôntico consiste na completa remoção dos materiais obturadores dos canais radiculares ${ }^{15}$, principalmente do terço apical ${ }^{14,16}$. A realização de uma reintervenção geralmente deve-se à contaminação existente e à persistência de materiais obturadores residuais que podem servir de meio ambiente para os micro-organismos, tornando difícil a desinfecção dos canais radiculares ${ }^{10}$. O sistema ProTaper Universal Retratamento (Dentsply/Maillefer, Suíça) é constituído por três instrumentos rotatórios de níquel-titânio (NiTi), nomeados D1, D2 e D3, de diferentes comprimentos, conicidades e diâmetros apicais ${ }^{3,16}$ e foi projetado para aperfeiçoar a eficiência na desobturação endodôntica e tornar o procedimento mais simplificado e com menor demanda de tempo ${ }^{12}$.

Devido à sua influência no sorriso, dentes anteriores endodonticamente tratados os quais apresentam descoloração pós-tratamento por erros técnicos são indicados para reintervenção $\mathrm{e}$ subsequentes procedimentos para recuperação da estética $^{6,9}$. O clareamento endógeno é um procedimento estético minimamente invasivo, o qual consiste em manter um agente clareador temporariamente no interior da câmara pulpar, sendo realizadas trocas periódicas ${ }^{6-8}$. Este tratamento promove resultados estéticos satisfatórios, sem a necessidade de maior desgaste da estrutura dentária, corroborando os princípios da Odontologia conservadora atual ${ }^{8-9}$.

Esta técnica é um procedimento confortável, de baixo custo e de natureza conservadora, permitindo $o$ retorno à cor natural de dentes escurecidos $^{6,9}$. Assim, o objetivo do presente estudo é relatar um caso clínico de retratamento endodôntico não cirúrgico, seguido de clareamento endógeno em dentes anteriores escurecidos para reabilitar os elementos tanto funcional quanto esteticamente.

\section{CASO CLÍNICO}

Paciente do gênero feminino, 25 anos, feoderma, estudante universitária, compareceu à clínica do curso de Odontologia de uma Universidade relatando insatisfação com seu sorriso. A queixa principal se fundamentava na baixa autoestima resultante do escurecimento dos elementos 21 e 22 após tratamento endodôntico realizado oito meses antes (Figura 1).

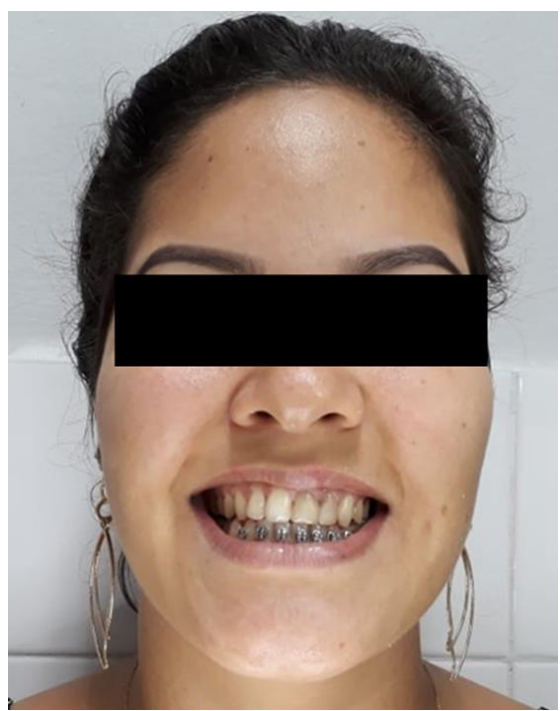

Figura 1: Fotografia frontal com nítido escurecimento dos elementos 21 e 22 .

$\mathrm{Na}$ consulta inicial realizou-se anamnese, verificando-se bom estado geral de saúde da paciente, e exame clínico, onde identificou-se restaurações nas faces proximais dos elementos 21 e 22 , além da presença de guta-percha exposta na face palatina e ausência de selamento coronário de ambos (Figura 2).

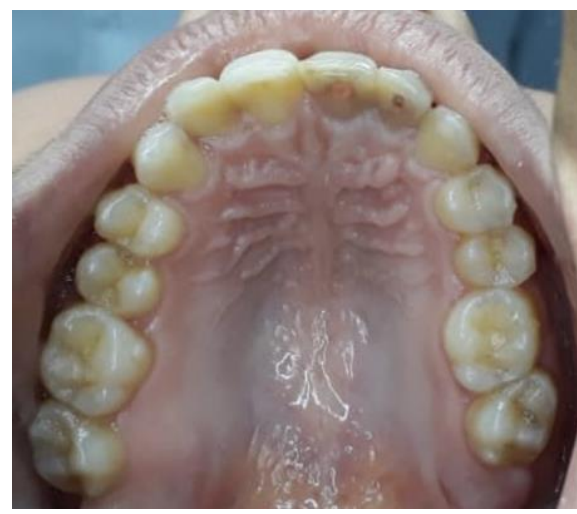

Figura 2: Fotografia intrabucal evidenciando ausência de selamento coronário.

Não foram realizados os testes de sensibilidade térmica pulpar em razão da presença de material obturador intracanal. Ao exame radiográfico notou-se material radiopaco no interior dos canais radiculares dos elementos 21 e 22 , compatível com obturação após tratamento endodôntico, além de sobre-extensão de material obturador além do ápice 
do elemento 21 e imagens radiolúcidas associadas à região apical de ambos os elementos (Figura 3). O plano de tratamento adotado para ambos os elementos foi a reintervenção endodôntica com posterior clareamento dentário interno e subsequente restauração coronária direta. Na primeira sessão de tratamento deu-se início ao procedimento com antissepsia, anestesia infiltrativa com cloridato de lidocaína $2 \%$ com epinefrina 1:100.000, isolamento absoluto, regularização da abertura coronária com a broca esférica diamantada \#1014HL. A remoção do material obturador foi efetuada com as limas D1, D2 e D3 do sistema rotatório ProTaper Universal Retratamento (Dentsply/Maillefer, Suíça) e irrigação copiosa com hipoclorito de sódio a 2,5\%. Com auxílio das limas F4 e F5 do sistema ProTaper Universal, o preparo biomecânico foi finalizado e a desobturação foi radiograficamente confirmada (Figura 4).
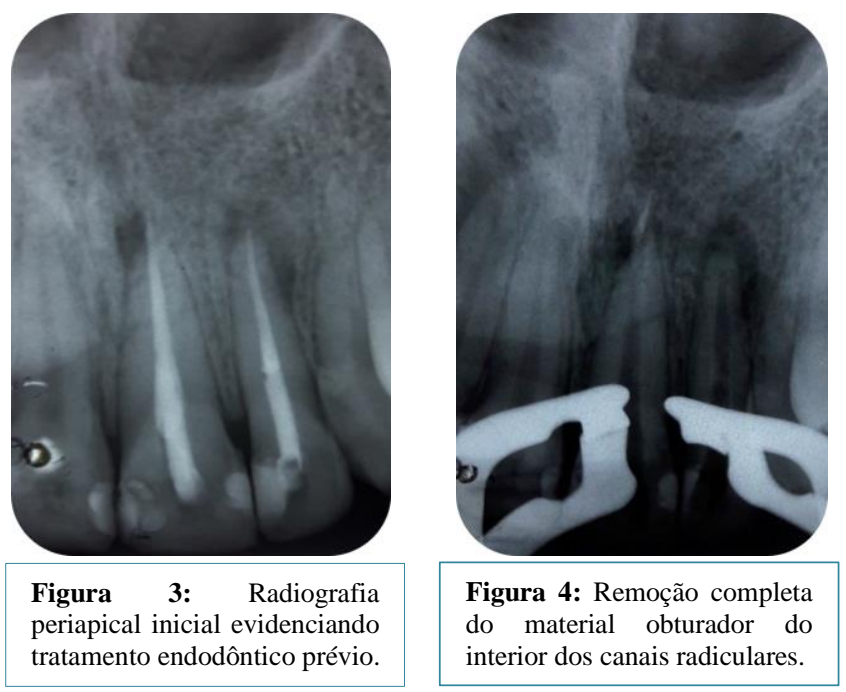

Realizou-se então a aplicação de medicação intracanal com pasta HPG, composta por hidróxido de cálcio (Biodinâmica, Brasil), paramonoclorofenol canforado (Biodinâmica, Brasil) e glicerina (Farmax, Brasil). Em seguida as cavidades foram seladas provisoriamente com cimento temporário (Coltosol, Vigodent, Brasil).

$\mathrm{Na}$ sessão seguinte continuou-se o procedimento com anestesia infiltrativa, isolamento absoluto, remoção do selamento temporário e irrigação abundante com hipoclorito de sódio a 2,5\% para remoção da medicação intracanal. Uma vez que o diâmetro apical do instrumento F5 corresponde à ponta de um instrumento $\# 50^{17}$, para a obturação de ambos os dentes foram selecionados cones de gutapercha convencional \#50, confirmados radiograficamente (Figura 5). A smear layer foi removida com agitação manual de EDTA a 17\% durante três minutos com auxílio de uma lima manual \#15, e a irrigação final foi realizada com hipoclorito de sódio a 2,5\%. Após a secagem dos canais com pontas de papel absorvente, foi realizada a obturação pela técnica de condensação lateral de guta-percha associada ao cimento AH Plus (Dentsply, Alemanha). Após corte dos cones, condensação vertical e limpeza das câmaras pulpares, cimento de ionômero de vidro (Maxxion R, FGM, Brasil) foi utilizado para restauração provisória das cavidades (Figura 6). Posteriormente, realizou-se a remoção do isolamento absoluto e a checagem da oclusão.

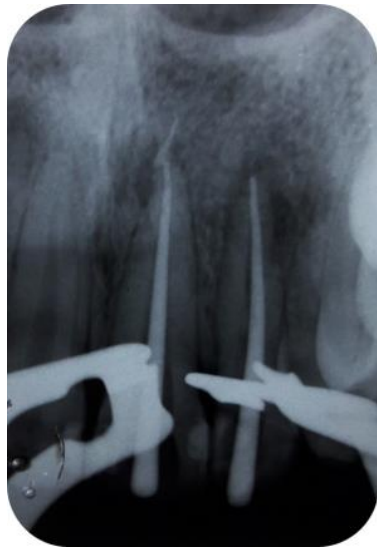

Figura 5: Prova radiográfica dos cones.

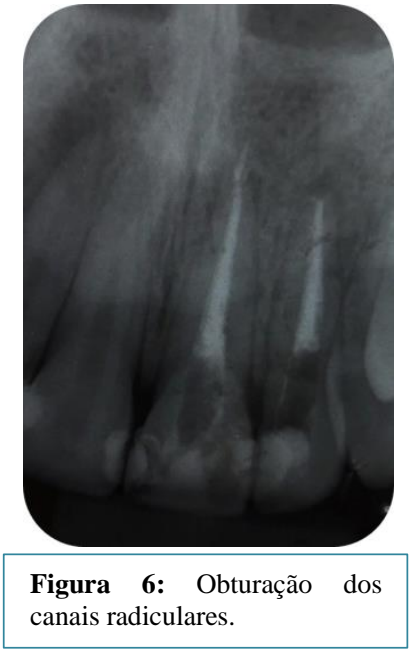

canais radiculares.
Trinta dias após a conclusão dos retratamentos endodônticos, iniciou-se o clareamento endógeno dos elementos 21 e 22. Realizou-se profilaxia com pedra-pomes e taça de borracha e registrou-se fotograficamente a cor inicial (Figura 7).

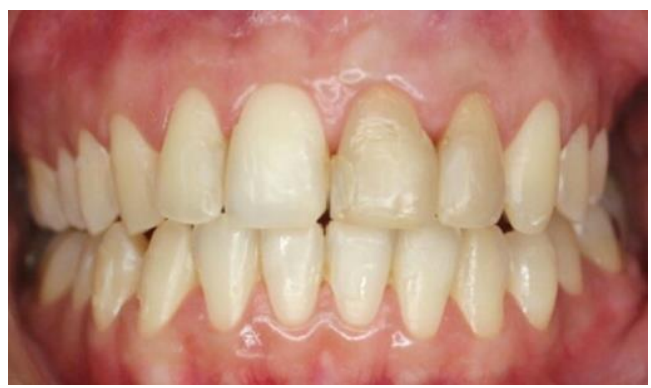

Figura 7: Aspecto inicial da cor dos dentes.

Em seguida, determinou-se a altura das coroas clínicas com sonda milimetrada, mensurandose a distância das bordas incisais até a gengiva marginal (Figura 8). Procedeu-se ao isolamento absoluto, reabertura coronária com auxílio da broca esférica diamantada \#1014HL, remoção de três milímetros de massa obturadora com brocas de Gates-Glidden \#5, irrigação das cavidades com hipoclorito de sódio a 2,5\% e secagem com algodão estéril.

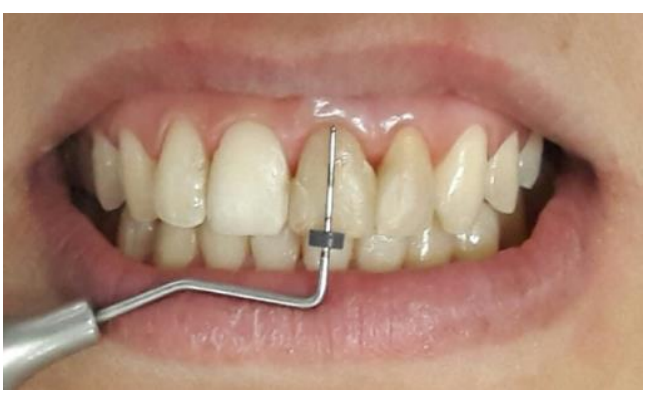

Figura 8: Mensuração da altura da coroa clínica do elemento 21. 
Confeccionou-se as barreiras cervicais com cimento de ionômero de vidro (Maxxion R, FGM, Brasil) com espessura de dois milímetros. Em seguida, aplicou-se o gel clareador de peróxido de carbamida a 37\% (Whiteness Super Endo, FGM, Brasil) no interior das câmaras pulpares, deixando-se um espaço de dois milímetros para a confecção das restaurações provisórias com cimento de ionômero de vidro. Após a remoção do isolamento absoluto, a oclusão foi verificada e radiografou-se para avaliação do selamento biológico cervical (Figura 9).

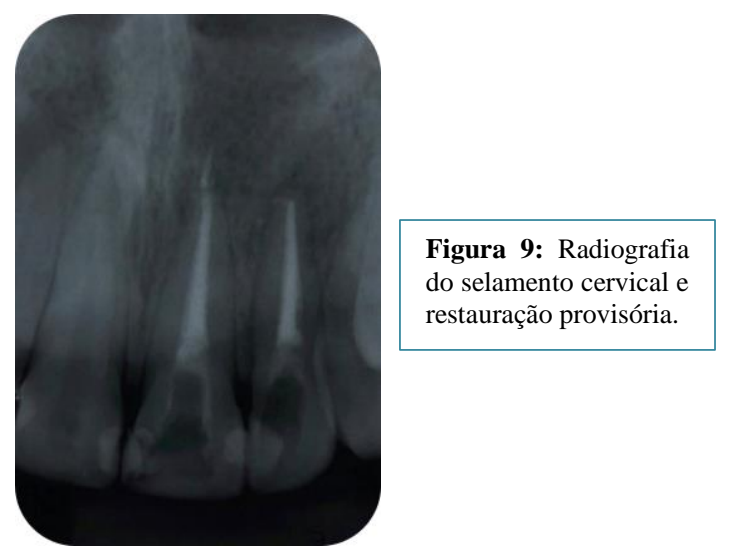

A paciente retornou após cinco dias exibindo nítida suavização do escurecimento de ambos os elementos (Figura 10). Realizou-se nova aplicação do gel clareador e, após mais cinco dias, evidenciou-se que o resultado almejado foi alcançado (Figura 11), interrompendo-se o clareamento.

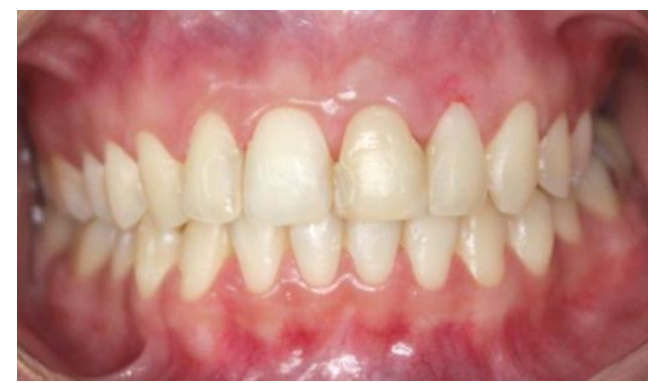

Figura 10: Registro após a primeira sessão de clareamento interno.

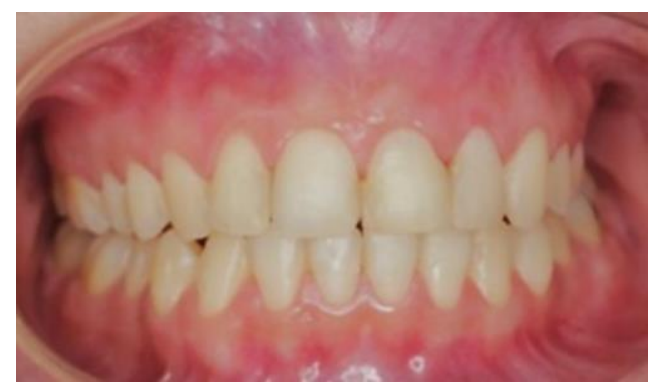

Figura 11: Registro após a segunda sessão de clareamento interno.

$\mathrm{O}$ agente clareador foi removido e as câmaras pulpares foram preenchidas com uma pasta de hidróxido de cálcio durante sete dias para neutralizar a ação do peróxido. Decorrido este período, realizouse as restaurações das faces palatinas e substituição das restaurações proximais com resina composta (Z250, 3M ESPE, Brasil) em ambos os elementos
(Figura 12). Uma semana após, realizou-se acabamento e polimento das restaurações e evidenciou-se o sucesso do tratamento (Figura 13).

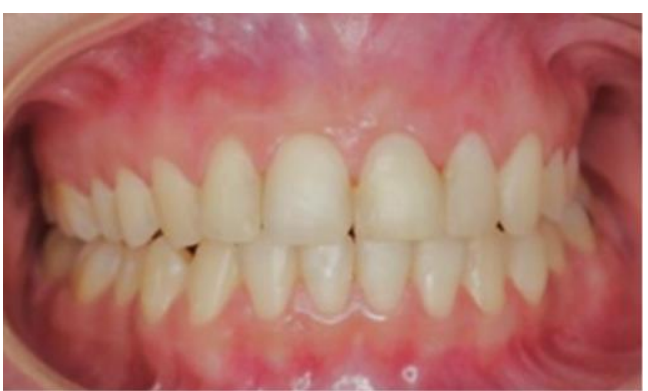

Figura 12: Aspecto após confecção das novas restaurações.

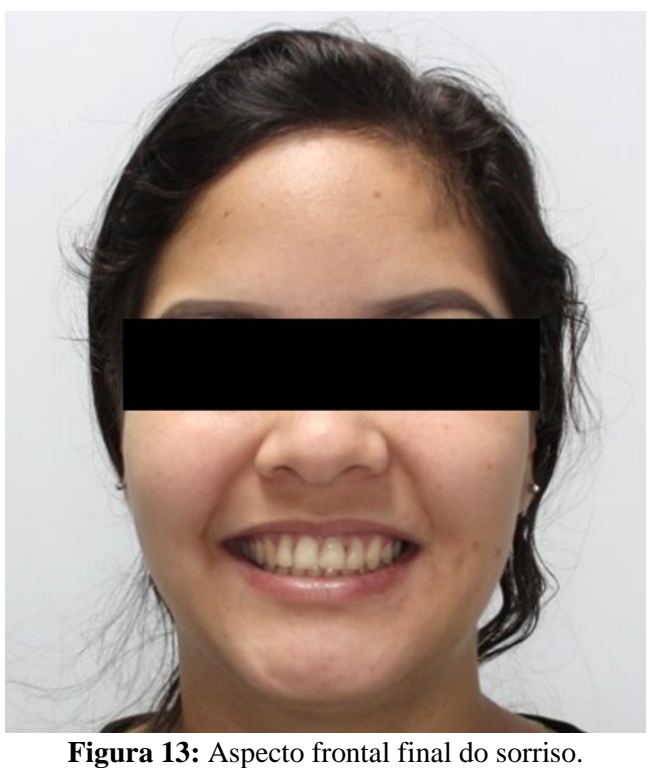

DISCUSSÃO

O insucesso do tratamento endodôntico pode ocorrer em virtude da gravidade de seus fatores etiológicos, eventos adversos durante a execução dos procedimentos ou pela falta de domínio técnico do operador $^{1}$. O inadequado preparo biomecânico do sistema de canais radiculares resulta em áreas intocadas as quais podem abrigar bactérias e restos necróticos nos túbulos dentinários, induzindo o surgimento ou a permanência de lesões periapicais ${ }^{5}$. Outro fator responsável por um baixo prognóstico é o inadequado selamento apical, resultante de extravasamento de materiais obturadores ou sobreobturação ${ }^{1,18}$.

A qualidade das restaurações também é fator determinante para o sucesso do tratamento endodôntico, uma vez que uma restauração coronária ausente ou de deficiente qualidade pode permitir a penetração de fluidos orais e micro-organismos rumo aos tecidos periapicais ${ }^{1,19}$. No presente relato, a permanência de material obturador na câmara pulpar parece ter induzido o escurecimento coronário. Além disso, a ausência de selamento coronário adequado e a sobreobturação possivelmente levaram ao insucesso do tratamento endodôntico, demandando uma nova intervenção endodôntica. 
As alterações de coloração nos elementos anteriores são rapidamente percebidas e são motivo de grande insatisfação por parte de pacientes jovens, podendo desencadear implicações psicológicas e comprometer a harmonia do sorriso, o bem-estar e a autoestima, necessitando uma intervenção profissional $^{6-8,17}$. Os fatores que levam ao escurecimento dentário podem variar em etiologia, aparência, localização e gravidade e podem ser classificados em pigmentações intrínsecas, extrínsecas ou uma associação de ambas ${ }^{9,20}$.

As pigmentações intrínsecas referem-se ao escurecimento no interior da estrutura dentária, cujos agentes etiológicos podem ser alterações sistêmicas tais como fluorose e uso de tetraciclina ${ }^{8}$, além de fatores locais, como necrose pulpar, hemorragia na estrutura interna do dente, traumatismo, medicação intracanal, remanescentes de tecido pulpar após tratamento endodôntico e persistência de materiais obturadores dentro da câmara pulpar ${ }^{8-9,20}$. Estes resíduos penetram nos túbulos dentinários, induzindo uma alteração de coloração $^{17}$. No caso clínico exposto, o escurecimento possivelmente ocorreu em virtude de um tratamento endodôntico previamente realizado nos elementos 21 e 22 . Radiograficamente observou-se sobre-extensão coronária de guta-percha em ambos, resultando em alteração de coloração.

Em situações de escurecimento póstratamento endodôntico, pode-se lançar mão de variadas opções de tratamento para reverter tal situação, desde as mais conservadoras, como o clareamento interno, ou optar por procedimentos mais invasivos, tais como facetas e coroas totais ${ }^{9,17}$. O clareamento interno, além de não demandar desgaste adicional de estrutura remanescente para restabelecer a cor natural do dente escurecido, permite a manutenção da forma e do contorno natural do dente e tem um baixo custo quando comparado a facetas, lentes de contato e coroas totais ${ }^{8,21}$. Além disso, o clareamento interno pode evitar situações indesejáveis relacionadas a próteses insatisfatórias, tais como problemas periodontais e alteração de oclusão $^{9,21}$. Tais situações foram norteadoras para a adoção da conduta clínica do presente caso.

As técnicas mais utilizadas atualmente para clarear dentes escurecidos tratados endodonticamente são as técnicas mediata (walking bleach), imediata e mista, com a associação de ambas, de acordo com o diagnóstico e a dificuldade de clareamento $^{7,9,17}$. A técnica termocatalítica, na qual aplica-se calor para acelerar a reação química dos géis clareadores, caiu em desuso devido ao alto risco de induzir reabsorção cervical externa ${ }^{8}$. Neste relato utilizou-se a técnica mediata por oferecer menores riscos de reações adversas nos tecidos perirradiculares, além de promover bons resultados.

Os géis clareadores mais adotados atualmente são o peróxido de hidrogênio, o perborato de sódio e o peróxido de carbamida, em diversas concentrações $^{9,22-25}$. O peróxido de hidrogênio induz resultados satisfatórios quando utilizado no clareamento interno; no entanto, quando utilizado em altas concentrações, está associado a um maior risco de reabsorção externa, devido à sua grande difusão extrarradicular ${ }^{23}$. O perborato de sódio pode ser utilizado em combinação com peróxido de hidrogênio ou com água destilada; no entanto, sua associação com água destilada pode demandar maior tempo clínico para produzir os efeitos desejáveis ${ }^{24}$. O peróxido de carbamida é o agente clareador de escolha para o clareamento interno, devido ao seu baixo nível de difusão extrarradicular e à sua desejável eficácia, promovendo bons resultados em curto intervalo de tempo, com menor risco de efeitos $\operatorname{adversos}^{9,22,24}$. As vantagens do peróxido de carbamida foram levadas em consideração na sua escolha para a conduta do presente relato.

Apesar de o clareamento interno ser uma técnica amplamente utilizada, a reabsorção cervical externa é um possível efeito adverso se não tomadas as devidas precauções ${ }^{7,21}$. A realização de uma barreira cervical com cerca de 2 a $3 \mathrm{~mm}$ de espessura na junção cemento-esmalte é essencial para a prevenção da reabsorção cervical externa ${ }^{22}$. Para sua confecção, diversos materiais podem ser utilizados, como cimento de fosfato de zinco, cimento de óxido de zinco e eugenol, resinas compostas e cimento de ionômero de vidro ${ }^{6,9}$. Optou-se no presente caso pela confecção de uma barreira cervical com cimento ionômero de vidro, devido à sua ampla indicação na literatura ${ }^{6,22-23}$, além de também servir de base para a restauração definitiva. Para a realização da restauração provisória entre as sessões do clareamento, optou-se pela utilização do cimento de ionômero de vidro por ser capaz de prevenir a microinfiltração na câmara pulpar ${ }^{26}$. Concluído o clareamento e antes da restauração definitiva, aplicou-se uma pasta de hidróxido de cálcio durante sete dias para neutralizar o $\mathrm{pH}$ da dentina e minimizar quaisquer possíveis riscos de reabsorção cervical externa $^{6,8,20}$.

\section{CONCLUSÃO}

O retratamento endodôntico não cirúrgico e o clareamento endógeno foram eficazes para a resolução do caso, pois possibilitaram a manutenção dos elementos dentários em função na cavidade oral e permitiram o restabelecimento da estética do sorriso, garantindo a satisfação da paciente.

\section{REFERÊNCIAS}

1. Torabinejad M, White SN. Endodontic treatment options after unsuccessful initial root canal treatment: alternatives to single-tooth implants. J Am Dent Assoc. 2016;147(3):214-20.

2. Mautone EP, Oliveira EPM, Bonatto SVS, Melo TAF, Queiroz MLP. Desobturação e repreparo do 
canal radicular: análise da eficácia de duas técnicas preconizadas. Rev Odontol Bras Central. 2014;23(64):58-64.

3. Mozardo DSB, Hussne RP, Nishiyama CK, Bodanezi A, Câmara AS. Efetividade de um sistema rotatório para retratamento na remoção da obturação de canais radiculares. Rev Assoc Paul Cir Dent. 2014;68(3):202-7.

4. Garcia JLO, Ramirez EC, Diego VD, López IRC, Rojas AR. Eficacia del sistema Protaper retratamiento en combinación con limas Hedstroem en conductos radiculares obturados con tres técnicas diferentes. Rev Endod Actual. 2013;8(2):4-11

5. Soares YSP, Azevedo SV. Retratamento endodôntico: possíveis causas do insucesso. Rev Cient In FOC. 2016;1(1):111-12.

6. Zimmerli B, Jeger F, Lussi A. Bleaching of nonvital teeth: a clinically relevant literature review. Schweiz Monatsschr Zahnmed. 2010; 120(4):306-20.

7. Schwendler A, Melara R, Erhardt MCG, Rolla JN, Souza FHC. Clareamento de dentes tratados endodonticamente: uma revisão da literatura. Rev Fac Odontol Porto Alegre. 2013;54(1/3):24-30.

8. Moretti LCT, Silva JRA, Prado RM, Fernandes KGC, Boer NCP, Simonato LE et al. Clareamento de dentes despolpados: relato de caso clínico. Arch Health Invest. 2017;6(5):213-17.

9. Greenwall-Cohen J, Greenwall LH. The single discoloured tooth: vital and non-vital bleaching techniques. Br Dent J. 2019;226(11):839-49.

10. Kaled GH, Faria MIA, Heck AR, Aragão EM, Morais SH, de Souza RC. Retratamento endodôntico: análise comparativa da efetividade da remoção da obturação dos canais radiculares realizada por três métodos. RGO Rev gauch odontol. 2011;59(1):103-8.

11. Rocha MP, Silva RV, Silva LRM, Rocha TCM, Brito AM, Pereira RP. Retratamento endodôntico não cirúrgico: relato de caso. Rev Odontol Univ Cid São Paulo. 2016;28(3):270-76.

12. Chandrasekar C, Ebenezer AVR, Kumar M, Sivakumar A. A comparative evaluation of gutta percha removal and extrusion of apical debris by rotary and hand files. J Clin Diagn Res. 2014;8(11):ZC110-14.

13. Kasam S, Mariswamy AB. Efficacy of different methods for removing root canal filling material in retreatment: an in-vitro study. J Clin Diagn Res. 2016;10(6):ZC6-10.

14. Ozyurek T, Tek V, Yilmaz K, Uslu G. Incidence of apical crack formation and propagation during removal of root canal filling materials with different engine driven nickel- titanium instruments. Restor Dent Endod. 2017;42(4):332-41.
15. Rubino GA, Candeiro GTM, Freire LG, Iglecias $\mathrm{EF}$, Lemos EM, Caldeira $\mathrm{Cl}$, et al. Micro-CT evalution of guta-percha removal by two retreatment systems. Iran Endod J. 2018; 13(2):221-27.

16. Kesim B, Ustun Y, Aslan T, Topçuoglu HS, Sahin $S$, Ulusan O. Efficacy of manual and mechanical instrumentation techniques for removal of overextended root canal filling material. Niger $\mathbf{J}$ Clin Pract. 2017;20(6):761-66.

17. Lucena MTL, Mantovani M, Fracalossi C, Silva GR. Clareamento interno em dentes desvitalizados com a técnica walking bleach: relato de caso. Uningá Review. 2015;24(1):33-9.

18. Ricucci D, Russo J, Rutberg M, Burleson JA, Spangberg LSW. A prospective cohort study of endodontic treatments of 1,369 root canals: results after 5 years. Oral Surg Oral Med Oral Pathol Oral Radiol Endod. 2011;112(6):825-42.

19. Gomes AC, Nejaim Y, Silva AIV, Neto FH, Cobenca N, Zaia AA et al. Influence of endodontic treatment and coronal restoration on status of periapical tissues: a cone-beam computed tomographic study. J Endod. 2015;41(10):1614-18.

20. Plotino G, Buono L, Grande NM, Pameijer CH, Somma F. Nonvital tooth bleaching: a review of the literature and clinical procedures. J Endod. 2008;34(4):394-407.

21. Abbott P, Heah SYS. Internal bleaching of teeth: an analysis of 255 teeth. Aust Dent J. 2009; 54(4):326-33.

22. Badole GP, Warhadpande MM, Bahadure RN, Badole SG. Aesthetic rehabilitation of discoloured nonvital anterior tooth with carbamide peroxide bleaching: case series. J Clin Diagn Res. 2013; 7(12):3073-76.

23. Madhu KS, Hegde S, Mathew S, Lata DA, Bhandi $\mathrm{SH}$, Shruthi N. Comparison of radicular peroxide leakage from four commonly used bleaching agents following intracoronal bleaching in endodontically treated teeth: an in vitro study. J Int Oral Health. 2013;5(4):49-55.

24. Mittal R, Sood AG, Singla MG, Dhawan D. A comparative evaluation of efficacy of commercially available bleaching agents in nonvital teeth: an in vitro study. Saudi Endod J. 2015; 5(1):33-7.

25. Moraru I, Taculinã M, Bãtãiosu M, Gheorghitã L, Diaconu O. Whitening non vital teeth: a case report. Curr Health Sci J. 2012;38(3):132-35.

26. Souza CR, Augusto CR, Aquino EP, Alves JC, Pires RP, Venâncio GN. Reabilitação estética de dente anterior escurecido: relato de caso. Arch Health Invest. 2017;6(8):377-81. 
http://dx.doi.org/10.21270/archi.v9i2.4757

\section{CONFLITO DE INTERESSES}

Os autores declaram não haver conflitos de interesse.

\section{AUTOR PARA CORRESPONDÊNCIA}

Tiago Silva da Fonseca

fonseca.tsf@gmail.com

Submetido em 06/08/2019

Aceito em 20/04/2020 